\title{
Reflexiones sobre la crisis financiera
}

\author{
Mg. Juan Anicama Pescorán \\ Econ. Jorge Paz López
}

\section{RESUMEN}

Es una reciente participación virtual en un Congreso sobre Globalización Financiera, ligado a la presente coyuntura mundial, lo que motiva el presente artículo para analizar e interpretar lo que está pasando en la economía sumida en una seria crisis que, en esencia, trasciende el ambiente financiero; y avanzar en la exposición de algunas de sus características, casi de la mano del transcurrir de la propia crisis.

Palabras clave: Globalización, financiero, real, crisis, recesión.

\begin{abstract}
It is a virtual participation in a recent congress on financial globalization, linked to this global environment, that motivates this article to analyze and interpret what is happening in the economy plunged into a serious crisis, which in essence is beyond the financial environment; progress in the exposure of some of its features, almost hand passing of the crisis.
\end{abstract}

Keywords: Globalization, financial sector, real sector, crisis, recession. 


\section{Juan Anicama Pescorán / Jorge Paz López}

\section{INTRODUCCIÓN}

En el mes de setiembre de 2008 estalló la actual crisis financiera y el retorno del Estado implementando mecanismos de rescate de empresas, tanto financieras como productivas, contrariando los postulados neoliberales de los defensores del mercado, con señales que permiten pensar en una crisis del modelo basado en el predominio absoluto del mercado, sin gobierno mundial y con escasas reglas para la economía y el trabajo.

Tales señales son movimientos contradictorios, pues al tiempo que se permite la quiebra de ciertas instituciones bancarias, a otras (aseguradoras) se las nacionaliza; y a empresas consideradas estratégicas por el volumen de empleo ocupado -como las automotrices- se les brinda recursos financieros.

Es pues un hecho importante la actual crisis de la economía capitalista mundial, donde países como EEUU, Japón, Alemania y otros están en recesión, expresando la profundidad y extensión de la crisis y el relativo fin del pensamiento neoliberal. Al respecto, Adrianzén ${ }^{1}$ afirma que en el reciente artículo de Joseph Stiglitz, "Capitalistas estúpidos", este afirma que esta crisis se ha producido no por las fallas del sistema económico, sino más bien por una sucesión de políticas, de intereses y de personajes que creían que los mercados al ajustarse solos no debían ser regulados, y transcribe:

"La filosofía de la desregulación pagó dividendos indeseados durante años. En noviembre de 1999, el Congreso revocó la Ley Glass-Steagall, culminación de un esfuerzo de cabildeo de US $\$ 300$ millones por las industrias bancarias y de servicios financieros, y liderado en el Congreso por el Senador Phil Gramm. La Ley GlassSteagall había separado desde hace tiempo a los bancos comerciales (que prestan dinero) y a los bancos de inversiones (que organizan la venta de bonos y valores); había sido promulgada como consecuencia de la Gran Depresión y debía limitar los excesos de esa era, incluidos los conflictos de intereses".

Esto denota que el capitalismo solo conoce los intereses de los que buscan el lucro sin reparar en los intereses de los otros, aun sean de su misma clase. La gran estafa de un prestigiado miembro de Wall Street -Bernard Madoff- que ha embaucado a bancos, fundaciones y millonarios del mundo, etc. por más de US\$ 50 mil millones, es

1 Adrianzén M, Alberto. "La izquierda y el fin del siglo XX". Artículo en La República del 20 de diciembre de 2008, pág. 19. 


\section{Reflexiones sobre la Crisis Financiera}

demostración de un capitalismo que se basa en la búsqueda del dinero fácil y la codicia; cumpliéndose inexorablemente la ley económica de la maximización de ganancias que le permite funcionar y al mismo tiempo crear las condiciones para las crisis.

Sin embargo, caben dos grandes precisiones que interesa tenerlas en cuenta: a) la pérdida de unos es ganancia de otros, por eso es importante saber quiénes son, y en qué sectores actúan; y b) el cuestionamiento al modelo neoliberal no implica que este no siga funcionando ni que se sigan difundiendo sus postulados en el ámbito académico. Por ello, es importante contribuir con el desarrollo de un debate sobre la necesidad de un pensamiento económico que explique y transforme la realidad.

\section{LA CRISIS DEL 29}

Varios analistas económicos afirman que la actual crisis financiera mundial tiene varios aspectos en común con la llamada gran depresión surgida en los Estados Unidos entre los años 1928 a 1934 -con repercusiones en el mundo entero-, y de la cual recién se pudo salir en 1945 mediante el denominado capitalismo de Estado; en el cual el Estado interviene activamente en la economía apoyando la creación de ganancias en tiempos de reanimación y prosperidad o en el rescate de empresas que apuntalan al sistema en tiempo de crisis. Además, políticamente se desenvolvió en una economía de guerra -primera y segunda guerra imperialista mundial y, en la actualidad la intervención en Irak y el histórico y desigual conflicto de Israel con Palestina-.

Se han elaborado hipótesis conducentes a establecer las causas de dicha depresión, en el que la teoría económica marxista, al hacer hincapié en el análisis de las grandes crisis, la atribuye a que:

"... la inmensa capacidad productiva con relación a la población que se desarrolla dentro del régimen capitalista de producción, y aunque no en la misma proporción, el aumento de los valores capitales (no solo el de su substracto material), que aumentan mucho más rápidamente que la población, se halla en contradicción con la base cada vez más reducida, en proporción a la creciente riqueza, para la que esta inmensa capacidad productiva trabaja, y con el régimen de valorización de este capital cada vez mayor" ${ }^{2}$.

$\overline{2}$ Marx, Carlos. El Capital. Tomo 3; Edit. F.C.E., pp. 262-263. 


\section{Juan Anicama Pescorán / Jorge Paz López}

En términos concretos, el desenvolvimiento del capitalismo lleva por un lado a una cada vez mayor concentración y centralización (adquisiciones y fusiones) del capital y, por otro lado, a una mayor socialización del trabajo que se manifiesta en una baja de la cuota general o media de la ganancia (rentabilidad del capital) y en el subconsumo; o sea, a la descoordinación entre producción y consumo. Donde la producción superó las necesidades reales de consumo a partir de 1925, sobre todo en los Estados Unidos, donde los stocks aumentaron conforme se reconstruían las economías europeas y, sustentada en la expansión del consumo de masas de dos sectores nuevos: los electrodomésticos y el automotriz (Gráfico N. ${ }^{\circ} 1$ ).

Gráfico N. ${ }^{\circ}$ 1. Automóviles utilizados por millón de habitantes, 1920-1940.

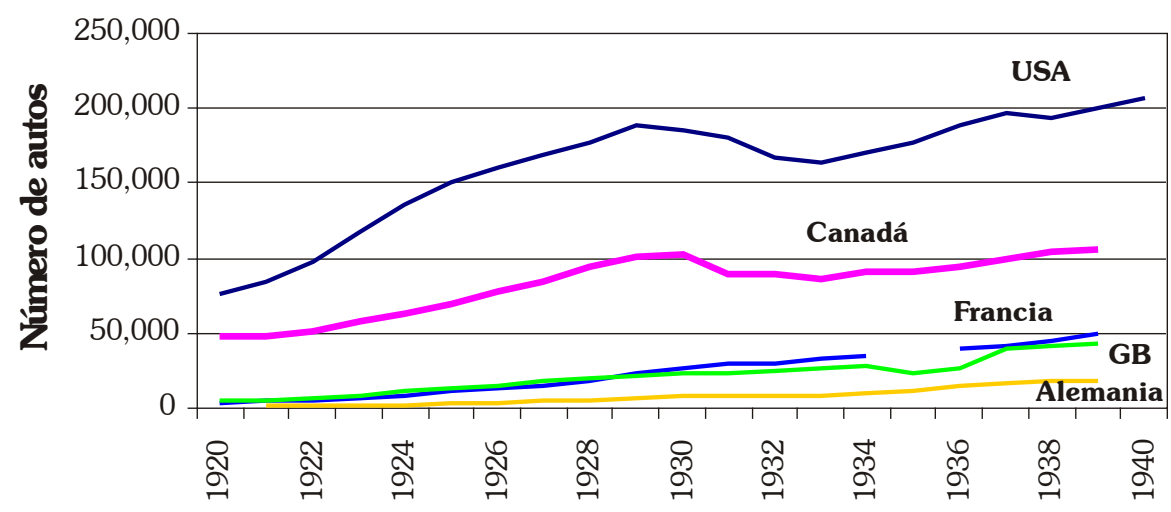

Año

Fuente: Rostow. The Stages of Economic Growth. p. 171.

Tal momento de expansión exigía el funcionamiento de un sistema monetario que facilitaría los intercambios, desde un centro financiero, mediante una divisa hegemónica. Pero esta relativa expansión de los años veinte se caracterizó por el marasmo monetario, la pérdida del patrón oro -recuperada en el breve periodo del 24 al 29- y la excesiva dependencia financiera de los Estados Unidos, convertido en el principal 


\section{Reflexiones sobre la Crisis Financiera}

acreedor, y con Wall Street como el centro financiero más importante del mundo que empezó a desplazar a Londres de la hegemonía financiera. Los dólares americanos invadieron Europa en busca de todo el que necesitara crédito.

La existencia de nuevos centros financieros como el de Wall Street, junto con los de Londres y París, originó una competencia de préstamos exteriores entre el dólar y la libra que generó ciertas dosis de inestabilidad; pero al final, los años veinte fueron buenos para los Estados Unidos, como dice Galbraith: "los más ricos se enriquecieron mucho más deprisa a que los pobres dejaran de serlo", enriqueciéndose rápidamente y con un mínimo esfuerzo. El ánimo especulativo fue tan grande que en Florida, se compraron terrenos que aumentaban de valor sin motivos aparentes; llegando a Wall Street con el alza que se produjo en las acciones ordinarias.

Los negocios eran rápidos y beneficiosos. Había muchos pequeños ahorristas que decidieron invertir, e hicieron de ello su forma de vida. Los agentes de bolsa prestaban a sus clientes tomando como garantía los propios títulos comprados, y, a su vez, pedían prestado a los bancos para comprar esos títulos, pues con las ganancias de la bolsa se podía pagar los créditos y sus intereses. Una situación de esta índole no podía continuar indefinidamente, ya que dependía exclusivamente del alza de la bolsa, y esta era ficticia, fruto exclusivo de la especulación y del mantenimiento de la creencia de que la economía de los Estados Unidos era inquebrantable.

La especulación, sin relación con la actividad económica real, llevó la bolsa a la quiebra. ¿Cómo y por qué se mantuvo esta situación especulativa? Las razones que se señalan son varias, pero podemos citar las siguientes:

- La inflación monetaria que dio como resultado una política de dinero barato y facilidad de créditos.

- La estructura bancaria que estaba formada por múltiples y pequeños bancos, cuya supervivencia financiera dependía del alza de los valores de bolsa. Prestaban casi siempre a corto plazo con un interés del 12 por 100, cuando ellos obtenían créditos de la "Reserva Federal" al 5 por 100. El negocio era bueno, pero los bancos dependían mucho de la especulación bursátil y contribuían al alza de los valores. Además, no existía control estatal ninguno sobre los bancos. 


\section{Juan Anicama Pescorán / Jorge Paz López}

- La existencia de compañías de "cartera" que poseían abundantes acciones y estaban interesadas en la subida de las cotizaciones.

- La psicología de las masas, convencidas de que el sistema era infalible, alentadas por capitalistas sin escrúpulos y políticos que no sabían o no querían acabar con ese estado de cosas.

Lo ocurrido el 29' en Wall Street ya es conocido y tiene parecido con la actual crisis, pues se ofertaban acciones que no eran demandadas y estas bajaban tremendamente en sus cotizaciones.

\section{80 AÑOS DESPUÉS}

Si bien la crisis financiera norteamericana explotó el 2008, las condiciones que la provocaron se venían gestando a partir del año 2001, cuando la Reserva Federal de Estados Unidos (FED) comenzó a bajar las tasas de interés que afectaban a todos los sectores para permitir la recuperación de la economía norteamericana.

Pero, a comienzos de 2006, la FED volvió a subir las tasas de interés para evitar un aumento de la inflación y parar de alguna forma este mecanismo, y lo que ya se empezaba a notar en la economía norteamericana: una burbuja. Una "burbuja financiera" es cuando, sin que haya razones fundamentales detrás, mucha gente compra algo por la percepción de que va a seguir subiendo de precio y al cambiar esa impresión, genera su explosión.

Cuando dejaron de subir los precios de las casas y las tasas de interés a pagar aumentaron, muchas de las hipotecas que se habían generado solo por la burbuja se convirtieron en imposibles de pagar. De otro lado, los que tenían los paquetes con derecho a cobrar por esas hipotecas comenzaron a ver que su valor bajaba, por lo que ya no se esperaba que se pagara nada, haciéndose cargo de las pérdidas de valor de sus activos basados en hipotecas; pero el asunto es que cuando la proporción de estos en el total de sus activos fue muy alta, reconocieron las pérdidas, originando que su patrimonio neto termine siendo nulo o negativo, llegando a la quiebra.

Esta situación de incertidumbre y búsqueda de lo seguro, se termina trasladando a todo el sistema financiero (estadounidense y mundial), afectando la generación de nuevos créditos en todo el globo. 


\section{Reflexiones sobre la Crisis Financiera}

José Antonio Ocampo ${ }^{3}$ señala: "La explicación básica es muy simple y fue analizada hace varias décadas por Hyman Minsky, un gran intelectual norteamericano, de moda hoy, pero ignorado por la ortodoxia económica, obsesionada por demostrar la eficiencia de los mercados. El problema fundamental es que a medida que avanza el auge, tiende a aumentar la confianza y los agentes financieros toman por ello, posiciones cada vez más riesgosas; en el sentido en que involucran mayor endeudamiento en relación con el capital que poseen (mayor "apalancamiento" para utilizar la jerga de la profesión)". O sea, la lógica de este modo de operar es contundente durante los auges, porque permite hacer grandes ganancias con poco capital, gracias a la inflación de los precios de los activos que se autogeneran. El auge termina por lo tanto, con niveles de endeudamiento excesivo de todos los agentes y escasa capitalización de las entidades financieras, que siembra las semillas de las quiebras de los deudores y de los intermediarios financieros.

\section{LA CRISIS DEL NEOLIBERALISMO}

Desde la década de los 70’s se aplicó en EEUU la idea neoliberal que con la globalización afectó la economía real de EE.UU., creando desocupación y destruyendo PYMEs, las cuales, a la falta de capital y la mala gestión de fondos, utilizaron fondos ajenos a costos superiores a la rentabilidad conseguida con su inversión o utilizaron fondos propios en proyectos con niveles de rentabilidad inferiores a sus costos de oportunidad. Esto es parte fundamental para explicar muchos fracasos de microempresas y PYMEs.

En los últimos 10 años, se dio tal abundancia de crédito barato que por el carácter del ciudadano norteamericano, este consumía más de lo que podía y comprando todo aquello que se importaba de las llamadas economías emergentes como China y la India. Y ante la falta de regulación, a pesar de la existencia de instituciones regulatorias, hubo un exceso de créditos baratos, dados a cualesquiera, no por bancos, sino por productores de hipotecas, quienes obtenían ganancias cuanto mayor número de hipotecas producía, alimentando la burbuja inmobiliaria que luego, finalmente, explotó; cuando los bienes hipotecados, tan sobrevaluados por la especulación, ya no cubrían

Ocampo, José Antonio. Profesor de la Universidad de Columbia. En: Portafolio p. 29, 10 de Octubre de 2007, Bogotá - Colombia. 


\section{Juan Anicama Pescorán / Jorge Paz López}

contablemente los patrimonios de los bancos, primero de los de inversión, y luego, por coparticipar, los comerciales.

El impulso a que existieran las hipotecas sub prime implicó que muchas propiedades se compraran con hipotecas dadas a quienes no podían pagarlas, y que las compraban porque las propiedades subían y subían, mientras los deudores iban pagando y vendiendo sucesivamente. Ahora, es conocido cómo estos instrumentos se convirtieron en "tóxicos", con un gran apalancamiento, reunidos en paquetes que se vendieron a firmas como Lehman Brothers, y otros, que a su vez cuando se dieron cuenta que contablemente no podían contar con las respectivas garantías, infectaron a otros bancos en forma global.

Los préstamos hipotecarios sub prime -se estima- alcanzaron los 600 mil millones de dólares en unos cuantos años, es decir, $20.1 \%$ del crédito hipotecario total. La mayor parte de ellos concentrados en unos cuantos bancos y agencias hipotecarias originadoras de tales créditos, como puede verse en el Cuadro $1^{4}$.

Cientos de miles de inversores que ponían su dinero para que estas organizaciones de hipotecas sub prime pudieran prestar alegremente a gente sin posibilidades de pagarlas, perdieron irremediablemente su dinero. A su vez, muchos compradores de buena fe, que estaban pagando su deuda, se encontraron que la deuda hipotecaria era muy superior al valor actualizado del bien, y decidieron entregar al banco y perder lo ya invertido.

En tales situaciones, la historia señala que en el capitalismo una crisis se inicia desde el sector real y repercute en el sector financiero; pero la crisis actual generada en EE.UU. se inicia en el sector financiero; cuando el 12 de julio se nacionaliza a las dos gigantes del crédito financiero e hipotecario: Fannie Mae y Freddie Mac y, posteriormente, el Departamento del Tesoro deja que quiebren dos importantes bancos como el Lehman Brothers y el Merrill Lynch -saliendo airosos bancos como el JP Morgan y el Goldman Sachs-, impactando ello en el sector real.

$4 \quad$ Tomado de Ponencia: "Consecuencias de la crisis crediticia estadounidense sobre el balance de los conglomerados financieros en 2007”, por Eugenia Correa y Cesar Duarte. En: VI Congreso Internacional sobre Globalización Financiera (www.eumed.net/eve Encuentros Virtuales de Economía). 


\section{Reflexiones sobre la Crisis Financiera}

El ex presidente de la FED, Paul Volcker, señaló que el mercado de las viviendas estadounidenses enfrenta aún más pérdidas y que la mayor economía del mundo ya está en recesión. Reconocido por su lucha contra la inflación de dos dígitos al final de la década de 1970, dijo que la prioridad para las autoridades de Estados Unidos en la crisis del crédito es estabilizar el sistema financiero, incluso a pesar de que eso implique una fuerte intervención del gobierno. En su participación en diversos eventos, sostuvo lo siguiente:

"La primera prioridad es estabilizar el sistema financiero. Es necesario incluso a pesar de que el costo involucrado es una pesada intrusión del Gobierno en mercados que deberían ser privados". "Los precios de las casas de Estados Unidos siguen bajando. Todavía vendrán más pérdidas. La economía, creo, está en recesión". "He visto muchas crisis pero nunca he visto algo como esto". "Esta crisis es una excepción. No creo que podamos escapar del daño a la economía real"5.

Un ejemplo de lo arriba dicho, se dio en Colombia en la década pasada, donde primero colapsó el sector real entre 1991 y 1997, y luego esta situación desencadenó la crisis del sector financiero entre 1997 y 1998. La intervención del gobierno en la crisis empresarial se limitó a legislaciones que pretendían facilitarle al empresario la refinanciación de sus obligaciones con los acreedores, pero no tenían medidas de carácter financiero. En el caso de la crisis del sector financiero, de inmediato, el gobierno estableció el Gravamen a los Movimientos Financieros, y de esta manera todos los colombianos (obligados por ley) participaron en la creación de un fondo para salvar el sector financiero. Esto pone en debate, si es más importante el sector financiero con su actuar autónomo o el real, y cómo el gobierno interviene con medidas de rescate.

El actuar autónomo del sector financiero se demuestra con el hecho de que los fondos públicos y privados de pensiones estadounidenses perdieron unos 2 billones de dólares, según un informe de la Oficina de Presupuesto del Congreso (CBO). Tal cifra revela los efectos devastadores de la crisis financiera sobre el ahorro de los asalariados. "Está claro que la seguridad de las pensiones de los estadounidenses podría pagar los platos rotos de esta crisis financiera", dijo, en un comunicado, el representante demócrata George Miller, que preside la Comisión de Educación y del Trabajo de la Cámara estadounidense.

5 http://www.lanacion.com.ar/nota.asp?nota_id=1059076 (martes 14 de octubre de 2008) 


\section{Juan Anicama Pescorán / Jorge Paz López}

Las caídas de las bolsas del mundo, desde el pasado "septiembre negro" de 2008, han puesto en cuestionamiento la arquitectura financiera internacional, donde el desplome de Wall Street es comparable, en la esfera financiera, a lo que representó en el ámbito geopolítico la caída del muro de Berlín. Paúl Samuelson, premio Nóbel de Economía, afirma: "Esta debacle es para el capitalismo lo que la caída de la Unión Soviética (URSS) fue para el comunismo". Se termina el período abierto en 1981 con la fórmula de Ronald Reagan: "El Estado no es la solución, es el problema". Durante décadas, los fundamentalistas del mercado repitieron que este siempre tenía razón, que la globalización era sinónimo de felicidad y que el capitalismo financiero edificaba el paraíso terrenal para todos. Se equivocaron.

El despilfarro efectuado por los banqueros de inversión, embelesados por la lógica de la rentabilidad a corto plazo y la búsqueda de beneficios exorbitantes; empresarios dispuestos a todo para sacar ganancias con ventas de corto plazo abusivas, manipulaciones, invención de instrumentos financieros opacos como la titulización de activos, contratos de cobertura de riesgos, hedge funds. (Fondos de Inversión Libre o Fondos de Cobertura basados en inversiones especulativas), con el objetivo de maximizar su rentabilidad, sea cual sea la tendencia del mercado), contagió a todo el planeta, conduciendo a la economía mundial a tomar la forma de una economía de papel, virtual, inmaterial, donde lo financiero llegó a representar más de 250 billones de euros, o sea seis veces el monto de la riqueza real mundial.

Estas llamadas innovaciones financieras han jugado un rol importante en esta crisis, por la magnitud considerable de sus transacciones caracterizadas por su total opacidad, donde:

"El mundo que viene es un mundo de especialistas y la prueba es que los dos bancos que cayeron, Lehman y Merrill Lynch, no estaban en manos de banqueros. En cambio sí lo están los que salieron airosos de la turbulencia, como JP Morgan y Goldman Sachs"6

Y de golpe, esa gigantesca "burbuja" reventó, con una banca de inversión casi borrada del mapa. Las cinco mayores entidades se desmoronaron: Lehman Brothers en bancarrota; Bear Stearns comprado con la ayuda de la FED por Morgan Chase; Merril

6 http://www.lanacion.com.ar: Artículo de Carlos Pagni (martes 7 de octubre de 2008) 


\section{Reflexiones sobre la Crisis Financiera}

Lynch adquirido por Bank of America; y los dos últimos, Goldman Sachs y Morgan Stanley (en parte comprado por el japonés Mitsubishi UFJ), reconvertidos en simples bancos comerciales.

Pero no solo la banca de inversión fue afectada, sino también los bancos centrales, los sistemas de regulación, los bancos comerciales, las cajas de ahorros, las compañías de seguros, las agencias de calificación de riesgos (Standard \& Poors, Moody's, Fitch) y hasta las auditorías contables (Deloitte, Ernst \& Young, PwC).

La administración del presidente George W. Bush tuvo que disponer la intervención del Estado. Las principales entidades de crédito inmobiliario, Fannie Mae y Freddy Mac fueron nacionalizadas. También lo ha sido el American International Group (AIG), la mayor compañía de seguros del mundo. Y el secretario del Tesoro estadounidense, Henry Paulson (ex-Presidente de la Banca Goldman Sachs) propuso un plan de rescate, reformado y aprobado por el Congreso de Estados Unidos, de las acciones "tóxicas" procedentes de las "hipotecas basura" (sub prime) por un valor de unos 700 mil millones de dólares, que también adelantará el Estado, o sea los contribuyentes.

Lo criticable es que las autoridades estadounidenses acuden al rescate de los "banksters" ("banquero-gangster") a expensas de los ciudadanos, cuando meses atrás el presidente Bush se negó a firmar una ley que ofrecía una cobertura médica a nueve millones de niños pobres por un costo de 4 mil millones de euros. Lo consideró un gasto inútil. Ahora, para salvar a los "banksters" de Wall Street nada le parece suficiente.

Del otro lado, el gobierno británico anunció un plan destinado a proporcionar a los bancos US\$ 90000 millones de nuevo capital, junto con amplias garantías para las transacciones financieras entre bancos. Estas intervenciones del Estado, las mayores, en volumen, de la historia económica, demuestran la falsedad de la hipótesis de la "mano invisible", de mercados que son capaces de regularse por sí mismos y que el sistema social global mejora las condiciones de vida de todos. Más bien, se confirma la ley del capitalismo: se privatizan los beneficios pero se socializan las pérdidas. Y ante una crisis, la intervención estatal no es nueva. 


\section{Juan Anicama Pescorán / Jorge Paz López}

Ante tal liberalización, la ortodoxia económica aceptó que las medidas de liberalización financiera debían estar acompañadas de una mayor regulación y supervisión prudencial. Pero esa prédica no se aplicó al centro del capitalismo financiero, que siguió desregulando su propio sistema; ni tampoco hubo ninguna regulación sobre las mencionadas "innovaciones financieras". Y, también la responsabilidad del Comité de Basilea, creado precisamente para dar pautas para el manejo del sistema bancario.

\section{EL IMPERIO AMERICANO}

Hechos como que los estadounidenses están endeudados y opiniones que Estados Unidos es un país endeudado, más allá de lo aconsejable, son evidentes. Solamente entre 2003 y 2004, el Estado Norteamericano transfirió a los fabricantes de armamentos, y a la construcción y reconstrucción, una suma enorme de US\$ 430 mil millones en 2003 y US\$ 413 mil millones en 2004. La Oficina de Presupuesto del Congreso dijo que el déficit para el año fiscal que acaba de finalizar (30 de septiembre de 2008) es US\$ 276 mil millones superior al saldo negativo de US\$ 162 mil millones registrado en el ejercicio fiscal 2007, conllevando a que el déficit presupuestario alcance un récord de US\$ 438 mil millones en el año fiscal 2008, debido al incremento en el gasto en defensa y menores ingresos originados por los problemas en los mercados financieros.

Esta situación llama a la atención sobre el hecho de que, una economía globalizada no puede aceptar la hegemonía de un país que, por demás, no está al parecer ni siquiera en condiciones de ejercerla. Tal cuestionamiento de potencia hegemónica y el fin de la era del dólar, incluso refrendada por Soros, parece ser una realidad palpable.

El economista Nouriel Roubini, profesor de la escuela de negocios Stern de Nueva York, en su obra La declinación del imperio americano, y desde su blog del Global EconoMonitor (www.rge.monitor.com/blog/roubini) adelantó la debacle financiera por la especulación con los créditos subprime desde 2004, y las razones que considera que hacen que esta sea la peor crisis financiera desde la Gran Depresión y la peor recesión de Estados Unidos en décadas. 


\section{Reflexiones sobre la Crisis Financiera}

En su artículo publicado: "La peor crisis financiera desde la Gran Depresión", se extraen párrafos principales como los siguientes ${ }^{7}$ :

- "La crisis financiera implicará pérdidas crediticias de por lo menos un billón de dólares, pero es más probable que lleguen a los 2 billones. La crisis financiera y bancaria será severa, durará varios años y conducirá a una dura y persistente crisis de liquidez y de crédito. Será la recesión estadounidense más grave en décadas. Cuando los efectos temporarios de la baja de impuestos desaparezcan, los consumidores estarán tambaleando en la cuerda floja. Es el comienzo de la declinación del Imperio Americano".

- "El precio de las acciones está muy bajo y hay riesgo de que se produzca un crac en ese mercado. Lehman y Merrill se fueron y dentro de poco Morgan Stanley y Goldman Sachs necesitarán también socios más grandes con bolsillos más profundos. La mayor aseguradora del mundo, AIG, está al borde de la bancarrota y docenas de otros bancos están en la misma situación. Está comenzando una corrida bancaria silenciosa a medida que se extiende el nerviosismo de los depositantes".

- "El rescate financiero del Tesoro a Freddie y Fannie es socialismo para los ricos, los que tienen contactos; y Wall Street es la continuación de un sistema corrupto donde las ganancias se privatizan y las pérdidas se socializan".

- "Cientos de bancos pequeños que tienen en promedio el 67 por ciento de sus activos en bienes inmuebles van a quebrar. Docenas de grandes bancos nacionales y regionales, que están en la misma condición dada su exposición en ese segmento del mercado, también van a quebrar. Inclusive algunos grandes bancos están en una situación de semi insolvencia y mientras que se los considera demasiado grandes para caer, su rescate con dinero de la Corporación Federal de Seguros de los Depósitos Bancarios (FDIC, por sus siglas en inglés) será extremadamente costoso."

- "En la cumbre de la crisis financiera de 1990-1991 cuando muchos bancos, como el Citibank, eran insolventes, la FEF utilizó herramientas parecidas a las que se usan ahora para rescatar a esas instituciones de la quiebra. Si una caída del 5 por ciento en el precio de las viviendas puso a la entidad en una situación de insolvencia, ¿qué efectos tendrá una caída del 30 por ciento, como la que se espera?".

7 Tomado del VI Congreso Internacional sobre Globalización Financiera (www.eumed.net/eve Encuentros Virtuales de Economía). 


\section{Juan Anicama Pescorán / Jorge Paz López}

- "La FDIC dispone sólo de US\$53 mil millones y se quedará seguro sin dinero cuando los bancos quiebren y se les deba pagar el seguro a los depositantes".

- "El precio de las acciones en EE.UU. y en el exterior caerá mucho más. En una recesión típica estos precios caen en promedio 28 por ciento desde el pico. Pero ésta no es una recesión común, los precios de los activos caerán alrededor del 40 por ciento en relación con su máximo".

- "El resto del mundo no se va a desacoplar de la recesión norteamericana. Se va a reacoplar, ya hay doce desarrolladas que están en camino a un aterrizaje forzoso recesivo. Por esta importante desaceleración global el petróleo, la energía y los commodities caerán entre 20 y 30 por ciento con respecto a sus picos de burbuja".

\section{UNA NECESARIA REFLEXIÓN}

La crisis actual no es solo del sistema financiero, sino afecta ya, en modo creciente, al conjunto del sistema económico, en primer lugar a la llamada economía real que es la que directamente produce bienes y servicios para la sociedad.

El estallido de la burbuja inmobiliaria ha generado también la explosión de la crisis energética y alimentaria, donde los especuladores y los políticos de los Estados Corporativos crearon zozobra en el mundo por el elevado precio que alcanzaron los principales commodities como el petróleo, minerales y productos agrícolas. Ahora, observamos cómo se derrumban esos falsos precios que pusieron en jaque la economía mundial, especialmente de los países en desarrollo.

El caso del petróleo es muy singular en ello, por un lado debido al nivel de recesión particularmente de la industria automotriz norteamericana que ha repercutido en economías de los países del llamado 'BRIC' (Brasil, Rusia, India y China) y, por otro lado, a que su mercado al estar ligado con los mercados financiero especulativos sufrió una enorme volatilidad en su precio. En el transcurso del año 2008, su precio llegó a un nivel máximo de US\$147/barril hasta un nivel mínimo por debajo de US\$ 40/barril. 


\section{Reflexiones sobre la Crisis Financiera}

En este aspecto, será importante considerar ideas centrales que se manejan en el contexto académico y político, como las vertidas por Carlos Marx desde el siglo XIX; porque el mundo en el cual vivimos hoy no puede entenderse sin comprender los problemas a los que se debe hacer frente. Él entendió que la constitución de una economía internacional globalizada era inherente al modo capitalista de producción y predijo que este proceso generaría no solamente el crecimiento y la prosperidad alardeados por políticos y teóricos liberales, sino también violentos conflictos, crisis económicas e injusticia social generalizada. Y que lo principal es intentar salvar al sector productivo, verdadero creador de riqueza y luego a los bancos.

Tal es el regreso al interés en Marx, al observarse una gran demanda en Alemania por su obra máxima El Capital, donde analizando el origen y devenir de la sociedad capitalista, explica las profundas contradicciones inmersas en ella, como la existente entre producción y valorización que se concretiza en el desarrollo de la capacidad productiva que crea cada vez más riqueza (objetos útiles) frente a la avidez de ganancia o afán de lucro; la contradicción entre producción y población que genera un exceso de población (desocupados) por el fuerte desarrollo de la capacidad productiva. Estas contradicciones encuentran salidas momentáneas a través de las crisis económicas autogeneradas con dimensiones políticas y sociales.

Ahora, no se podrá creer en la prédica neoliberal, dominante durante los últimos 20 años, de que el capitalismo se ha establecido para siempre, que la historia tenía un fin o, en efecto, que cualquier sistema de relaciones humanas podría ser para siempre, final $y$ definitivo.

Está pues en cuestionamiento, los implacables ajustes del FMI con su contradictoria recomendación de expansión fiscal en los países desarrollados y no para los países subdesarrollados. Por eso, un pensamiento económico distinto a ser aplicado en nuestro país es sumamente necesario, este debe tomar, principalmente, en cuenta, la histórica inequitativa distribución de la riqueza que se agudiza -cada vez más- con el privilegio de la concentración de las elevadas tasas de ganancias y, la exoneración a las empresas transnacionales del pago del impuesto a las ganancias que obtienen de las operaciones especulativas de su capital en la Bolsa de Valores de Lima. 


\section{Juan Anicama Pescorán / Jorge Paz López}

\section{CONCLUSIONES}

La crisis no es solamente financiera, sino que se ha convertido en una crisis de la economía real, que se manifiesta en una recesión. Los gobiernos centrales no previeron o no le dieron la importancia que tenían las claras señales antes del 2008; quedando comprobado que el mercado no es suficiente, por ser meramente especulativo y que el Estado debe vigilar y hacer cumplir las leyes; cerrando el paso a la especulación financiera e impidiendo la alteración ficticia de los precios y de los valores de las acciones en las bolsas.

La canalización del gasto público a los rescates financieros, el paro económico, el deterioro salarial, son los costos de las crisis financieras. Incluso en los países desarrollados, que característicamente tienen una distribución del ingreso menos concentrada que en los países en desarrollo y en donde los índices de pobreza son menores; de todas maneras el retroceso en el bienestar y el deterioro en la calidad de vida son severos.

Existe paralelismo con la crisis del 29 -en especial en las bolsas-, en términos de la enorme volatilidad por un lado, y las medidas que se están tomando como la intervención directa de los gobiernos para evitar el derrumbe mediante la inyección masiva de capital, con el objetivo de restablecer la confianza. La intervención estatal en el sistema financiero ya es un hecho en todos los países y en esto, hasta los que lo rechazan, han tenido que usarlo. El problema para la economía norteamericana y mundial radica en lo siguiente: ¿Cuál debe ser el nivel de intervención estatal en las finanzas y en la economía y cómo se podrá interpretar y repercutir ello a nivel mundial?

Por último, la crisis financiera que vive el mundo actualmente es un fenómeno al que debemos analizar en el campo académico y político para interpretar cuáles son y serán los grandes problemas que se derivan y se derivarán de ello; esto es para tomar medidas y que de algún modo no afecten tan lacerantemente a los países en vías de desarrollo.

\section{COMENTARIO}

En el libro llamado El por qué y cómo hacemos las cosas es de enorme importancia en los negocios [y en la vida], cuyo autor es Dov Seidman, ejecutivo de LRN, un organismo que ayuda a las empresas a construir una cultura corporativa ética, argumenta que en 


\section{Reflexiones sobre la Crisis Financiera}

nuestro mundo hiperconectado y transparente, la manera en que uno hace las cosas es más importante que nunca, porque ahora hay tanta más gente que puede ver cómo uno hace las cosas, y que le cuenta a otros por internet, sin costo y sin ninguna restricción.

Seidman dice que "En un mundo conectado los países, los gobiernos y las empresas también tienen carácter, y su carácter (cómo hacen lo que hacen, cómo cumplen sus promesas, cómo toman decisiones, cómo ocurren realmente las cosas en su interior, cómo se conectan y colaboran, cómo engendran confianza, cómo se relacionan con sus clientes, con el medio ambiente y con las comunidades) es su destino".

Nos alejamos de todos esos cómo. Es decir, nos alejamos de un mundo en el que si uno quería una hipoteca para comprar una casa, tenía que demostrar ingresos reales y antecedentes crediticios. Caímos en un mundo en el que un banquero podía venderle una hipoteca y hacer un montón de dinero por adelantado y después endosarle su hipoteca a un "empaquetador" que armaba un paquete con otras hipotecas, las dividía en bonos y se las vendía a bancos tan remotos como los de Islandia.

El banco que concedía la hipoteca se alejó del cómo porque simplemente traspasaba, a usted y a su hipoteca, a un empaquetador. Y el banco de inversiones que armaba paquetes con esas hipotecas se alejó del cómo porque no lo conocía a usted, pero sí sabía que era lucrativo juntar sus hipotecas con otras en un paquete. Y la calificadora de riesgo que daba valor a esos créditos se alejó del cómo porque se podía hacer muchísimo dinero asignando un buen valor a esos bonos. Y entonces, ¿para qué examinar las cosas en gran profundidad?

Y el banco de Islandia se alejó del cómo porque si todo el mundo compraba esos bonos y las ganancias eran buenas, ¿̇por qué no hacerlo? "El lema de los bancos UBS es: "Usted y nosotros». Pero el mundo que creamos era en realidad "Usted y nadie». En término de valores, nadie estaba realmente conectado", dijo Seidman. "Partes de Wall Street se desconectaron de hacer cualquier inversión en emprendimientos humanos... ayudar a las empresas a crecer y adoptar nuevas ideas." En cambio, se dedicaron a idear maneras de convertir el dinero en más dinero.

(Tomado de Comentarios del VI Congreso Internacional sobre Globalización Financiera www.eumed.net/eve Encuentros Virtuales de Economía). 